University of Wollongong

Research Online

Faculty of Social Sciences - Papers (Archive) Faculty of Arts, Social Sciences \& Humanities

2013

The effects of a multi-component higher-functioning autism anti-stigma program on adolescent boys

Jessica J. Staniland

University of Wollongong, js808@uowmail.edu.au

Mitchell K. Byrne

University of Wollongong, mbyrne@uow.edu.au

Follow this and additional works at: https://ro.uow.edu.au/sspapers

Part of the Education Commons, and the Social and Behavioral Sciences Commons

Research Online is the open access institutional repository for the University of Wollongong. For further information contact the UOW Library: research-pubs@uow.edu.au 


\title{
The effects of a multi-component higher-functioning autism anti-stigma program on adolescent boys
}

\begin{abstract}
A six-session higher-functioning autism anti-stigma program incorporating descriptive, explanatory and directive information was delivered to adolescent boys and the impact upon knowledge, attitudes and behavioural intentions towards peers with autism was evaluated. Participants were seventh-, eighth- and ninth-grade students $(\mathrm{N}=395)$ from regular classes in a mainstream school. Two-eighth-grade classes were randomly allocated to the intervention condition and all remaining students were either allocated to the no-intervention peer or no-intervention non-peer condition. The anti-stigma program improved the knowledge and attitudes, but not the behavioural intentions of participants towards their peers with autism. Knowledge and attitudinal changes were maintained at follow-up. There were no spill-over effects of the program to non-targeted students. These results provide some preliminary evidence for the effectiveness of multi-session anti-stigma programs incorporating combined information for adolescent students in inclusive educational environments.
\end{abstract}

\section{Keywords}

boys, higher, adolescent, program, multi, stigma, effects, anti, autism, component, functioning

\section{Disciplines}

Education | Social and Behavioral Sciences

\section{Publication Details}

Staniland, J. J. \& Byrne, M. K. (2013). The effects of a multi-component higher-functioning autism antistigma program on adolescent boys. Journal of Autism and Developmental Disorders, 43 (12), 2816-2829. 
Running head: HIGHER-FUNCTIONING AUTISM ANTI-STIGMA PROGRAM

The Effects of a Multi-Component Higher-Functioning Autism Anti-Stigma Program on Adolescent Boys Jessica J. Staniland and Mitchell K. Byrne University of Wollongong

Jessica J. Staniland, Department of Psychology, University of Wollongong, NSW, AUSTRALIA; Mitchell. K. Byrne, Department of Psychology, University of Wollongong, NSW, AUSTRALIA. Correspondence concerning this article should be addressed to Mitchell K. Byrne, Department of Psychology, University of Wollongong, Northfields Avenue, Wollongong, NSW, AUSTRALA, 2522; Tel: +61 4221 5310; Fax: +61 24221 4163; Email: mbyrne@uow.edu.au. 
HIGHER-FUNCTIONING AUTISM ANTI-STIGMA PROGRAM 2

\begin{abstract}
A six-session higher-functioning autism anti-stigma program incorporating descriptive, explanatory and directive information was delivered to adolescent boys and the impact upon knowledge, attitudes and behavioural intentions towards peers with autism was evaluated. Participants were seventh-, eighth- and ninthgrade students $(\mathrm{N}=395)$ from regular classes in a mainstream school. Two eighth-grade classes were randomly allocated to the intervention condition and all remaining students were either allocated to the no-intervention peer or no-intervention non-peer condition. The anti-stigma program improved the knowledge and attitudes, but not the behavioural intentions of participants towards their peers with autism. Knowledge and attitudinal changes were maintained at follow-up. There were no spill-over effects of the program to non-targeted students. These results provide some preliminary evidence for the effectiveness of multi-session anti-stigma programs incorporating combined information for adolescent students in inclusive educational environments.
\end{abstract}

Keywords: higher-functioning autism; knowledge; attitudes; behavioural intentions; peers

Jessica J. Staniland and Mitchell K. Byrne

Corresponding author email information: mbyrne@uow.edu.au. 
Contemporary educational philosophy with regard to children with special needs places a high value on education that is as close as possible to that of non-disabled children (Kasari, Freeman, Bauminger and Alkin, 1999). Recent public awareness of this philosophy has led to a surge in the number of children with autism spectrum disorders (ASDs) being educated in inclusive settings such that integration into mainstream educational environments is now considered the norm (Campbell, Morgan and Jackson, 2003). This is especially the case for those non-intellectually disabled children with Autism Spectrum Disorder, (previously referred to as Asperger's Disorder or higher-functioning autism: HFA) who display no cognitive impairments (Ferraioli and Harris, 2011) ${ }^{1}$. However, since the emergence of this trend, there has been some concern over the degree to which typically developing children accept their HFA peers (Swaim and Morgan, 2001). While some prior research has suggested that typically-developing children report positive attitudes towards their disabled peers in an inclusive educational setting (McDonald, Birnbrauer and Swierissen, 1987), these observations were relative to the attitudes of peers in non-inclusive educational environments. Indeed, more recent research has found that typically developing peers may hold pejorative views toward their disabled peers regardless of the inclusivity of setting (Campbell, Ferguson, Herzinger, Jackson and Marino, 2004; Harrower and Dunlap, 2001). Further, Gray $(1993,2002)$ has suggested that the stigma associated with HFA may even be worse than that associated with other mental health conditions, since odd or disruptive behaviour coupled with a lack of any physical abnormalities can result in peers attributing personal blame to either the children or their parents.

The present study investigates factors which may reduce the stigmatisation of HFA students in inclusive educational environments. In particular, the study examines the effect of a multi-session HFA anti-stigma program using descriptive, explanatory, and directive information on the knowledge, attitudes and behavioural intentions of typically-developing adolescents towards their HFA peers in a mainstream school.

\section{Youth Mental Health Anti-Stigma Initiatives}

There have been widespread calls to address the stigma associated with ASDs (Campbell, 2006; Ling, Mak and Cheung, 2010; Swaim and Morgan, 2001). However, given that the trend to include children with HFA in mainstream school environments is only recent, there have been far fewer anti-stigma interventions developed and evaluated for HFA than for other mental health conditions. Those that have been established generally based their methods upon those outlined in the mental health anti-stigma literature. This literature has identified three forms of intervention which target children without mental health conditions: education, contact,

\footnotetext{
${ }^{1}$ [INSERT FOOTNOTE 1.HERE]
} 
and a combination of the two. These interventions have focussed on changing the knowledge, attitudes, and/or behavioural intentions of those without mental health conditions towards their peers with mental health conditions. Educational interventions have been found to produce small, short-term changes in the attitudes of adolescents towards their peers with mental health conditions (Essler, Arthur and Stickley, 2006; Watson et al., 2004). However, positive personal contact with persons experiencing mental health conditions has been reported to be a more successful anti-stigma intervention and the combination of education with positive personal contact has been found to be more effective than each of the interventions alone (Chan, Mak and Law, 2009; Corrigan et al., 2001; Pinfold et al., 2003; Pinfold, Thornicroft, Huxley and Farmer, 2005; Schulze, Richter-Weling, Matschinger and Angermeyer, 2003; Wallach, 2004). Further, it has been suggested that school-based antistigma programs are particularly effective (Crisp, Gedler, Rix, Meltzer and Rowlands, 2000; De Ponte, 2000; Townley, 2002). Corrigan et al. (2005) argue that adolescents are one of the best targets for such programs, since it is during this development period that foundations are laid for adult attitudes and beliefs, which if positive, could prevent stigmatising behaviour in the future.

Despite the substantial development in school-based mental health anti-stigma initiatives, a variety of criticisms remain. In their review of the literature, Schachter et al. (2008) found few examples of reliable and valid interventions due to the failure on the part of many studies to use randomised controlled trials, employ appropriate control groups and/or adequately control (by design or analysis) both across and within study groups for confounding pre-, on- or non-study influences. Furthermore, Schachter et al. (2008) noted that nearly all studies were short-term evaluations of brief or single opportunity interventions which were conducted under naturalistic conditions (e.g. classrooms). That is, they note that there is a dearth of research on interventions implemented over a number of sessions, weeks, months or semesters. Nonetheless, Schachter et al. (2008) do conclude that the research to date has provided some preliminary evidence for the effectiveness of school-based anti-stigma interventions and has offered enough suggestive evidence to inform future research. They suggest this should take the form of multiple-session school-based interventions which are implemented repeatedly both within and over the school years as early as possible and which employ direct contact with individuals experiencing mental health difficulties.

\section{Youth HFA Anti-Stigma Initiatives}

The existing literature on youth HFA anti-stigma initiatives has examined the effect on typicallydeveloping children of three types of information provision: (1) descriptive information, which emphasises the 
degree of similarity between HFA children and their peers; (2) explanatory information, which emphasises the lack of control those with HFA have over their disorder; and (3) directive information, which provides instruction and guidance on how to respond to children with HFA (Campbell, 2006).

Swaim and Morgan (2001) examined the effect of an intervention using explanatory information on typically-developing children's attitudes and behavioural intentions towards a peer with HFA behaviours. Following Weiner's attribution theory (Weiner and Graham, 1984), the authors sought to determine whether children's attitudes towards their HFA peers would be more positive if they viewed the disorder as being beyond their peer's control. They found that explanatory information provided via a short video showing a boy with HFA behaviours had no significant positive effect on typically-developing children's attitudes or behavioural intentions. However, the study failed to include a manipulation check to determine if the information provided to participants actually led them to 'understand' that the disorder was out of the child's control. Furthermore, the video used to depict a child with HFA and provide explanatory information of the disorder was of short duration (2 minutes and 15 seconds in length), and thus possibly too short to accurately inform participants about HFA. Finally, it is also conceivable that a video representation of HFA behaviour may not evoke the same response in participants as real-life observations or interactions.

Extending Swaim and Morgan’s (2001) study, Campbell et al. (2004) examined the combined effects of descriptive and explanatory information on peers' attitudes and behavioural intentions towards a child with HFA. Their results revealed that compared with descriptive information alone, the combination of descriptive and explanatory information resulted in (1) improved third- and fourth-graders' but not fifth-graders' attitudes towards the child with HFA, and (2) improved behavioural intentions for all participants; however, girls were more responsive to information than boys. The authors explain the grade differences by proposing that the younger participants were more susceptible to the influence of an adult providing the voice-over message than were the older participants. They suggest that since fifth-graders are entering adolescence, they are more likely to be influenced by peers rather than adults. If this was indeed the case, then an adolescent voice over may have been more effective. Whilst Campbell et al.’s (2004) intervention proved more successful than Swaim and Morgan's (2001), it still failed to address the limitations in their study such as including a manipulation check for the information provided, increasing the length of the video and/or intervention presented or including a reallife interaction with an individual with HFA.

Campbell (2007) sought to address the grade discrepancy found in Campbell et al. (2004) by using a same-aged student to deliver information regarding HFA. He found that the combination of descriptive and 
explanatory information resulted in improved knowledge for all participants compared to descriptive information alone. Furthermore, combined information indirectly improved the attitudes of participants who had previously heard of autism, and the social behavioural intentions of all participants via increased perceived similarity. Campbell (2007) also improved on his earlier (Campbell et al., 2004) research and that of others (Swaim and Morgan, 2001) by including a manipulation check for message type. However, he still failed to address the other limitations of previous studies. Moreover, Campbell’s (2007) sample included an over-representation of females and as such may have skewed the results because girls are more likely to respond positively towards individuals with disabilities than boys (Campbell, 2006; Rosenbaum, Armstrong and King, 1988). Furthermore, neither Campbell’s 2007 study nor the studies upon which it was based (Swaim and Morgan, 2001; Campbell et al., 2004) included pre-test or follow-up measures of all variables, and thus it is unknown whether the results were directly related to the interventions delivered or if they were lasting.

Directive information has also been used in attempts to facilitate the inclusion of HFA students in mainstream schools (IRCA; 2001; Lisser and Westbay, 2001). However, to date, there have been no empirically tested studies using directive information. This is despite the fact that Campbell (2006) has posited that a persuasive message that includes descriptive, explanatory and directive information may prove to be the most effective message in altering children’s attitudes towards their peers with HFA.

Overall, although the literature suggests that there is some preliminary evidence for the effectiveness of school-based HFA anti-stigma programs, there remain several gaps in the research to date. First, unlike the mental health anti-stigma literature, there is little research on interventions which incorporate face-to-face contact with an individual experiencing HFA. Instead, interventions have tended to use videos depicting children with HFA. However, as previously observed, it remains unknown whether such videos elicit the same response as physical contact. Second, there appears to be a scarcity of research on multi-session interventions, which may result in longer-lasting effects than single-session interventions. Third, the research in the area is lacking examples of studies using pre-test measures to determine the true effects of interventions, and follow-up measures to assess maintenance of change. Fourth, despite literature suggesting that adolescents are one of the best targets for anti-stigma programs, few researchers have addressed this age group. Finally, the efficacy of directive information as a means for augmenting knowledge, attitude and behavioural change has not yet been documented in the literature. 
The present study aimed to address the gaps in the HFA anti-stigma literature by evaluating the effects of a multi-session HFA anti-stigma program using descriptive, explanatory and directive information. Similar to previous research, the targets for change were the knowledge, attitudes and behavioural intentions of adolescent boys towards their HFA peers in a mainstream school. The intervention combined education with both direct and video contact with individuals experiencing HFA. The study used pre-, post- and follow-up-measures of knowledge, attitudes and behavioural intentions. In addition, the study sought to extend the current literature by including online reflection and discussion activities in the program due to their demonstrated efficacy in education interventions (Nguyen, Carrieri-Kohlman, Rankin, Slaughter and Stulbarg, 2004), and by measuring whether the effects of HFA anti-stigma programs can 'spill-over' to non-targeted students (Leach and Byrne, 1986; Rydell et al., 2005).

Based on the literature, the following hypotheses were proposed:

(1): Following the HFA anti-stigma program, those individuals in the intervention condition will have more knowledge about HFA, more positive attitudes towards their peers with HFA, and improved behavioural intentions to engage with their peers with HFA.

(2): Following the HFA anti-stigma program, there will be some spill-over effects, such that the same grade peers in the no-intervention peer condition will have more knowledge about HFA, more positive attitudes towards their peers with HFA, and improved behavioural intentions to engage with their peers with HFA, but these changes will occur to a lesser extent than for those in the intervention condition.

(3): Following the HFA anti-stigma program, there will be no change in knowledge about HFA, attitudes towards peers with HFA, or behavioural intentions to engage with peers with HFA for the different grade non-peers in the no-intervention non-peer condition.

(4): Observed changes in knowledge about HFA, attitudes towards peers with HFA, and behavioural intentions to engage with peers with HFA will be sustained until the following school term for all conditions: (school terms in Australia average 10 weeks and are separated by school holidays of 2 weeks during the calendar year).

Methods

\section{Participants}


Participants were 395 boys (146 seventh-, 112 eighth-, and 137 ninth-graders) from regular classes in an independent catholic school in a predominantly middle-class suburb of a large metropolitan area. The all-boys school was selected because research has found that almost five times as many boys as girls are diagnosed with Autism Spectum Disorders (Centers for Disease Control and Prevention, 2012), and because a significant minority (5-10\% as estimated by the school’s 'Targeted Programs’ coordinator) of students enrolled in each grade at the school have HFA, which is greater than the estimated prevalence reported in the literature (BaronCohen et al., 2009). Participants were recruited through parent and student informed consent forms sent home with all students in the targeted year-groups. A total of $17 \%$ of students declined to participate. Two eighthgrade classes were randomly allocated to the intervention condition $(n=46)$. The remaining eighth-grade classes were allocated to the no-intervention peer condition $(n=66)$ which was used as a test for spill-over effects. All of the seventh- and ninth-grade classes were allocated to the no-intervention non-peer condition ( $n=283)$ which was used as a control condition. Due to the author's specific interest in assessing non-autistic student's perceptions of their HFA peers, those classes containing a significant proportion of identifiable students with HFA were not eligible for random allocation to the intervention condition. However, these classes were eligible for allocation to either the no-intervention peer condition, or the no-intervention non-peer condition, depending upon the grade of the students. All participants received community service hours (a Social Justice Curriculum requirement of Catholic School's education) for their participation.

\section{Procedure}

After providing written consent, all participants completed measures in a 20-minute interval during rollcall as a pre-test of knowledge, attitudes and behavioural intentions. One week following this, those classes who had been allocated to the intervention condition began an autism anti-stigma program designed by the authors, entitled 'Understanding Our Peers'. The program consisted of six weekly 50-minute sessions run by the firstnamed author during alternate school periods. Each of the intervention classes attended these sessions separately and classes were not combined for any sessions. Following each session, participants were asked to complete an online reflection and contribute to an online discussion on the schools web-based extranet. For a detailed session-by-session outline of the program, see Appendix. It should be noted that two participants dropped out of the intervention following session one of the program. All participants in the no-intervention peer and nointervention non-peer conditions attended their regular classes during the periods when the program was being administered. One week following and one term following the completion of the program, all participants again 
completed the measures in a 20-minute interval during roll-call as a post-test and follow-up test of knowledge, attitudes and behavioural intentions.

\section{Measures}

The Autism Knowledge Questionnaire (AKQ). The AKQ is a 10-item multiple-choice measure designed by the authors which addresses the key learning points of the intervention (e.g. "someone with autism may stand too close because they...?”). For each item, participants are instructed to circle the most correct answer from four possible options. The multiple-choice measure yields a total score out of 10 . The measure was piloted with a group of 15 adolescent boys prior to the commencement of the study to ascertain its reliability, readability and time for completion. Appropriate adjustments were made based upon item analysis and written feedback. The AKQ was used as a measure of participants’ knowledge of HFA. The AKQ is available from the corresponding author upon request.

Adjective Checklist (ACL). The ACL (Siperstein, 1980; Siperstein and Bak, 1977) is a self-report measure of cognitive attitudes which has been used extensively in research examining school students' attitudes towards children with disabilities. The measure lists 32 adjectives; 16 which are positive (e.g. “smart”) and 16 which are negative (e.g. “dumb”). Participants were instructed to circle all adjectives that describe their autistic peers. The ACL is scored by subtracting the total number of negative adjectives endorsed from the total number of positive adjectives endorsed and adding a constant of 20. The ACL has been found to have moderate to high internal consistency with Cronbach’s alpha’s ranging from .81 to .91 (Siperstein, 1980; Swaim and Morgan, 2001). The Cronbach’s alphas for the current sample were .88 at pre-test, .87 at post-test and .86 at follow-up. The ACL has also demonstrated construct validity as evidenced by significant Pearson correlations with measures of behavioural intentions (.76 for the Foley Scale, 0.67 for the Activity Preference List, .35 for the Selman’s Friendship Activity Scale, .46 for the Shared Activities Questionnaire; Siperstein, 2006). The ACL was used as a measure of participants’ attitudes towards their HFA peers.

Shared Activities Questionnaire (SAQ). The SAQ is a 24-item self-report scale developed to assess the behavioural intentions of primary school students to engage in social, academic and recreational activities with a target child or target children (Morgan, Walker, Biebrich and Bell, 1996). A modified version of the SAQ has been validated for adolescents (Campbell, 2008) and this version was used in the current study. The scale’s items are grouped according to three domains: (1) social (e.g. "be good friends with [target child/ren] at school”, (2) academic (e.g. "study spelling words with [target child/ren] at school”, and (3) recreational (e.g. "go to the 
movies with [target child/ren]”). Participants were instructed to circle one of five answers indicating how they felt about sharing each activity with their peers with autism, ranging from 1 (no, definitely not), through to 5 (yes, definitely). The measure yields a total score and a score for each domain. The modified version of the SAQ has been shown to have high internal consistency, with Cronbach’s alphas of .92 for the social domain, .92 for the academic domain and .94 for the recreational domain (Campbell, 2007). The Cronbach’s alphas for the total score for the current sample were .96 at pre-test, .97 at post-test and .97 at follow-up. Morgan et al.’s (1996) three-factor structure was also confirmed for adolescents (Comparative Fit Index = .92; Root MeanSquare Error of Approximation =.79; Campbell, 2008). The SAQ was used as a measure of participants’ behavioural intentions towards their HFA peers.

Similarity Rating Form-Revised (SRF-R).The original SRF was a three-item self-report scale developed to assess how similar participants think they are to a target or target children (e.g. "how much is/are [target child/ren] like you?”) (Campbell, 2005a). Campbell (2005a) found the scale had a Cronbach’s alpha of .67 for middle school students. The SRF was revised by adding three additional items designed by the researchers in an attempt to increase its reliability. The Cronbach’s alphas for the current sample were .75 at pre-test and .82 at post-test. Participants were instructed to circle the answer that indicates how similar or different they feel they or their classmates are to their peers with autism. The four answer choices ranged from 1 (very different), through to 4 (very much the same). The revised measure yields a total score out of six. The SRF-R was used a check that the descriptive information used in the intervention resulted in an increase in perceived similarity between HFA children and their peers.

Perceived Responsibility Questionnaire (PRQ-R). The PRQ was a four-item self-report measure developed to assess how much control participants think a target child or target children have over their behaviour (e.g. “[target child/ren] can control what he/they is/are doing”) (Campbell 2005a). Campbell (2005a) found the scale had a Cronbach's alpha of .56 for middle school students. The PRQ was also revised by adding four additional items designed by the researchers to the existing scale in an attempt to increase its reliability. The PRQ-R Cronbach’s alphas for the current sample were .75 at pre-test and .76 at post-test. Participants were instructed to circle the answer that indicates how true or false they believe a number of statements about their peers with autism to be. The four answer choices ranged from 1 (very false), through to 4 (very true). The amended measure yields a total score out of eight. The PRQ-R was used as a check that the explanatory information used in the intervention resulted in a decrease in the perceived personal responsibility of HFA children’s behaviours. 
Student Interaction Questionnaire (SIQ). The SIQ is a 10-item multiple-choice measure designed by the authors which reviews the main strategies taught in the intervention for appropriately engaging with HFA children in different situations (e.g. “your autistic peer won’t stop talking about a particular topic”). Each item of the measure represents a different situation where interaction with a child with HFA would likely occur. For each item, participants are instructed to rate the appropriateness of two different responses to the example interaction situation ensuring that one response was more appropriate than the other. The seven ratings are +3 (highly appropriate response), +2 (appropriate response), +1 (marginally appropriate response), 0 (neither appropriate nor inappropriate), -1 (marginally inappropriate response), -2 (inappropriate response), and -3 (highly inappropriate response). The items are marked according to whether the participant rates the more appropriate response as higher than the less appropriate response. The measure yields a total score out of 10.

The measure was piloted with a group of 15 adolescent boys prior to the commencement of the study to ascertain its reliability, readability and time for completion. Appropriate adjustments were made based upon item analysis and written feedback. The SIQ was used as a check that the directive information used in the intervention resulted in an increase in participants' understanding of how to interact with children with HFA. The SIQ is available from the corresponding author upon request.

\section{Data Analysis}

The manipulation checks were analysed using paired samples t-tests to determine if the various types of information used in the intervention resulted in the expected changes on the associated measures. One-way ANOVA's were conducted to determine if there were any significant differences between conditions on the key variables for change at pre-test. A 3 (time: pre-test, post-test, follow-up) x 3 (condition: intervention, nointervention peer, no-intervention non-peer) mixed design ANOVA with time as the within-subjects factor and condition as the between-subjects factor was the initial analysis for the results of all hypotheses. Main effects and all possible interactions were assessed to determine the outcome of the intervention on each of the key variables for change. Given significant interaction effects, follow-up analyses were undertaken. Specifically, one-way ANOVA's were conducted to determine whether there were any differences between conditions at each time point. If significant, Tukey HSD post-hoc comparisons were undertaken to determine which conditions differed at which time points. Repeated measures ANOVA's were conducted to determine whether there were any differences across time for each condition. If significant, paired samples t-tests were undertaken to determine which time points differed for which condition. Unexpectedly, a large number of participants failed to 
complete all of the online activities within the program so one-way ANOVA's were conducted to determine if there were any significant differences between no, low and high online activity users on the key variables for change at post-test and follow-up. Effect sizes were calculated for all significant effects. An alpha level of .05 was used for all statistical tests, except where adjustments to control the type 1 error rate are specified. In cases where the assumption of sphericity was violated, Greenhouse-Geisser adjustments were made.

Results

For all data, the assumption of normality was met, enabling the use of parametric analyses.

\section{Manipulation Checks}

Descriptive Information. The paired samples t-test revealed that participants in the intervention condition rated their peers with HFA as significantly more similar to themselves and the rest of their classmates at post-test $(M=17.47, S D=3.37)$ than at pre-test $(M=11.72, S D=2.95), t(42)=-8.8, p<.001, d=1.34$, indicating that the descriptive information manipulation was effective.

Explanatory Information. The paired samples t-test revealed that participants in the intervention condition rated their peers with HFA as having significantly less personal responsibility for their behaviour at post-test $(M=15.00, S D=3.77)$ than at pre-test $(M=12.60, S D=3.43), t(42)=3.51, p=.001, d=.53$, indicating that the explanatory information manipulation was effective.

Directive Information. The paired samples t-test revealed that participants in the intervention condition were able to correctly differentiate between more appropriate and inappropriate responses to interactions with their HFA peers at post-test $(M=5.84, S D=2.13)$ than at pre-test $(M=8.05, S D=1.75), t(42)=-5.9, p<.001$, $d=.90$, indicating that the directive information manipulation was effective.

Taken together, these results indicate that the 6-session HFA anti-stigma program successfully targeted the key variables for change.

\section{Intervention Effects on Key Variables for Change}

Table 1. presents the means and standard deviations for participants' scores on the AKQ, ACL and SAQ at pre-test, post-test and follow-up. Preliminary analyses indicated no significant differences between 
conditions at pre-test on knowledge, $F(2,316)=.07, p=.93$, attitudes $F(2,303)=2.38$, $p=.09$, or behavioural intentions, $F(2,313)=2.17, p=.12$.

[INSERT TABLE 1. HERE]

Knowledge About HFA. The mixed design ANOVA resulted in a significant main effect for time, $F(2,410)=48.80, p<.001, \eta p 2=.19$, a significant main effect for condition, $F(2,205)=34.62, p<.001, \eta p 2$ $=.25$, and a significant time $\mathrm{x}$ condition interaction, $F(4,410)=42.51, p<.001, \eta p 2=.19$. Follow-up one-way ANOVA's revealed significant differences between conditions at post-test, $F(2$, 337) $=69.73, p<.001, \eta p 2=$ .29 , and at follow-up, $F(2,380)=36.47, p<.001, \eta p 2=.16$. Post-hoc comparisons using the Tukey HSD test indicated that participants in the intervention condition $(M=7.62, S D=2.27)$ had significantly more knowledge about HFA at post-test than did those in the no-intervention peer condition $(M=4.53, S D=1.94), p<.001$, and those in the no-intervention non-peer condition $(M=3.95, S D=1.69), p<.001$. Participants in the intervention condition $(M=7.35, S D=2.07)$ also had significantly more knowledge about HFA at follow-up than those in the no-intervention peer condition $(M=4.65, S D=1.89), p<.001$, and those in the no-intervention non-peer condition $(M=4.41, S D=1.88), p<.001$.

Follow-up repeated measures ANOVA’s revealed significant differences between the pre-test, post-test and follow-up times for the intervention condition, $F(2,54)=51.81, p<.001, \eta p 2=.83$ but not for the nointervention peer condition, $F(2,68)=2.65, p=.08$, or the no-intervention non-peer condition, $F(2,288)=2.74$, $p=.06$. Paired samples t-tests using an adjusted alpha of .02 (.05/3) indicated that participants in the intervention condition had significantly more knowledge about HFA at post-test $(M=7.54, S D=2.29)$ than at pre-test $(M=4.27, S D=1.39), t(36)=-8.02, p<.001, d=1.32$, and at follow-up $(M=7.25, S D=2.08)$ than at pre-test $(M=4.16, S D=1.35), t(31)=-9.35, \mathrm{p}<.001, d=1.65$. No significant differences in knowledge were found between post-test $(M=8.00, S D=1.98)$ and follow-up $(M=7.54, S D=2.29), t(29)=1.18, p=.25$ for the intervention condition. Taken together, these results indicate that the six-session HFA anti-stigma program had an effect on participants’ knowledge of HFA but had no effect on same grade or different grade non-participants' knowledge of HFA. Specifically, individuals who attended the program had more knowledge about HFA after the program than before it, and this knowledge was maintained until the following school term. No such changes were found for individuals who did not attend the program, indicating that there were no spill-over effects of knowledge to non-targeted students. Comparatively, those individuals who attended the program had 
more knowledge about HFA immediately after and one term after the program than their peers in the same grade and their non-peers in different grades.

Attitudes Towards Peers with HFA. The mixed design ANOVA resulted in a significant main effect for time, $F(2,392)=4.34, p=.01, \eta p 2=.02$, a non-significant main effect for condition, $F(2,196)=.24, p=.79$, and a significant time $\mathrm{x}$ condition interaction, $F(4,392)=3.15, p=.01, \eta p 2=.03$. Follow-up one-way ANOVA’s revealed no significant differences between conditions at post-test, $F(2,328)=.79, p=.46$, or follow-up, $F(2,370)=.46, p=.63$. However, this lack of difference between conditions may be attributed to the fact that at baseline/pre-test, the intervention group had slightly poorer attitudes toward HFA peers than did the comparison groups, thus attenuating between-condition significance. This was born out by within-group analyses, with follow-up repeated measures ANOVA's revealed significant differences between the pre-test, post-test and follow-up times for the intervention condition, $F(2,52)=5.47, p=.01$, $\eta p 2=.17$ but not for the no-intervention peer condition, $F(2,60)=1.57, p=.22$, or the no-intervention non-peer condition, $F(2,280)=$ 2.00, $p=.14$. Paired samples t-tests using an adjusted alpha of .02 (.05/3) indicated that participants in the intervention condition had significantly more positive attitudes towards their peers with HFA at post-test $(M=$ 22.42, $S D=4.08)$ than at pre-test $(M=19.31, S D=4.07), \mathrm{t}(34)=-4.03, \mathrm{p}<.001, d=.68$, and at follow-up $(M=$ 21.58, $S D=5.66)$ than at pre-test $(M=19.19, S D=4.11), t(30)=-2.62 p=01, d=.47$. No significant differences in attitudes were found between post-test $(M=22.60, S D=4.17)$ and follow-up $(M=21.40, S D$ $=5.75), t(29)=1.04, p=.31$ for the intervention condition. Taken together, these results indicate that the sixsession HFA anti-stigma program had an effect on participants’ attitudes towards their peers with HFA but had no effect on same-grade or different grade non-participants’ attitudes towards their peers with HFA. Specifically, individuals who attended the HFA anti-stigma program had more positive attitudes towards their peers with HFA after the program than before it, and these attitudes were maintained until the following school term. No such changes were found for individuals who did not attend the program, indicating that there were no spill-over effects of attitudes to non-targeted students. However, comparatively, those individuals who attended the program did not have more positive attitudes towards their peers with HFA immediately after or one term after the program than their peers in the same grade and their non-peers in different grades.

Behavioural Intentions Towards Peers With HFA. The mixed design ANOVA resulted in a nonsignificant main effect for time, $F(2,402)=1.51, p=.22$, a non-significant main effect for condition, $F(2,201)=$ $.99, p=.37$, and a non-significant interaction between time and condition, $F(4,402)=.62, p=.65$. These results 
indicate that the six-session HFA anti-stigma program had no effect on participants’ or non-participants’ intentions to engage with their HFA peers.

\section{Online Activity Usage Effects}

The one-way ANOVA’s revealed no significant difference between no, low and high online activity users' knowledge at post-test $F(2,36)=2.37, p=.11$, but a significant difference between their knowledge at follow-up, $F(2,31)=5.14, p=.01, \eta p 2=.25$. Post-hoc comparisons using the Tukey HSD test indicated that high online activity users $(M=9.00, S D=1.26)$ had significantly more knowledge about HFA at follow-up than those who used no online activities $(M=6.44, S D=1.82), p=.02$. It should be noted that no significant differences were found between no, low and high activity users' knowledge at pre-test, $F(2,42)=1.35, p=.27$, and thus it is not the case that high online activity users had more knowledge about HFA at baseline. No significant difference was found between no, low and high online activity users 'attitudes at post-test $F(2,36)=$ 1.16, $p=.33$, or follow-up, $F(2,31)=.06, p=.95$. No significant difference was found between no, low and high online activity users' behavioural intentions at post-test, $F(2,35)=.02, p=.98$ or follow-up, $F(2,31)=$ $.12, p=.89$. Taken together, these results indicate that participants who completed all or nearly all of the online activities within the six-session HFA anti-stigma program had more knowledge about HFA one term following the program than those who completed none of the online activities. However, there were no differences between the various online activity users’ attitudes or behavioural intentions towards their HFA peers following the program.

\section{Discussion}

This study examined the effect of a six-session HFA anti-stigma program using descriptive, explanatory and directive information on the knowledge, attitudes and behavioural intentions of typically-developing adolescent boys towards their HFA peers in a mainstream school. Overall, the results indicated that an intervention of this type and length can have an impact on the knowledge and attitudes, but not on the behavioural intentions of adolescent boys towards their HFA peers.

The specific results as they pertain to the experimental predictions are as follows. First, as predicted, following the anti-stigma program, individuals in the intervention condition had more knowledge about HFA and more positive attitudes towards their HFA peers. However, contrary to prediction, there were no associated 
improvements to their behavioural intentions to engage with their HFA peers. Second, contrary to prediction, following the anti-stigma program, the same grade peers in the no-intervention condition did not have more knowledge about HFA, more positive attitudes towards their peers with HFA or improved behavioural intentions towards their peers with HFA. This suggests there were no spill-over effects of the intervention to non-targeted students. Third, as predicted, for the different grade non-peers in the no-intervention condition, there was no change in knowledge about HFA, attitudes towards peers with HFA, or behavioural intentions to engage with peers with HFA. Fourth, as predicted, the observed changes in the knowledge and attitudes of individuals in the intervention condition were sustained at the next assessment during the following school term.

Although not predicted, it was observed that online activity usage affected the degree to which participants' knowledge of HFA improved over time. Participants who engaged in high online activity usage had more knowledge one term following the anti-stigma program than those who engaged in no online activity usage. Online activity usage did not affect the degree to which participants' attitudes or behavioural intentions towards their HFA peers improved over time.

Of particular note is the difference in the magnitude of the effects of the HFA anti-stigma program on the variables for change. Comparatively, the effect of the program on participants’ knowledge was considerably larger (i.e. effect sizes ranging from $\eta \mathrm{p} 2=.16$ to $\eta \mathrm{p} 2=.83$ and from $d=1.32$ to $d=1.65$ ) than the effect on participants’ attitudes (i.e. effect sizes ranging from $\eta p 2=.02$ to $\eta p 2=.17$ and from $d=.47$ to $d=.68$ ). Although the attitudinal differences between conditions at pre-test suggested relatively poorer attitudes in the intervention condition, this difference was not significant. However, the relatively small attitudinal effect sizes observed may account for the failure of the intervention to produce a significantly different attitudinal score between conditions at post-test and follow-up in that the magnitude of change required was greater.

The results of this study are consistent with those that have found some efficacy for school-based mental health anti-stigma interventions using a combination of education and positive personal contact (e.g. Chan et al., 2009; Corrigan et al., 2001; Pinfold et al., 2003; Pinfold et al., 2005; Schulze et al., 2003; Wallach et al., 2004). Furthermore, the results are also consistent with those that have found some efficacy for HFA antistigma programs utilising a combination of information types (e.g. Campbell et al., 2004; Campbell, 2007). The present study improved upon both the methodology and intervention of like previous research and as such reported enhanced outcomes. For example, while Campbell (2007) found no direct effect of the intervention on adolescents’ attitudes, the current study did report attitudinal improvement, albeit a relatively small effect. It is possible that the design improvements of the current study (e.g. including physical contact with an individual 
with HFA and using multiple intervention sessions) are responsible for the discrepancy between the two studies’ attitudinal results.

The results of this study are inconsistent with Leach and Byrne’s (1986) finding that the effects of a secondary school behaviour reinforcement program had some positive spill-over effects to non-targeted students. The finding of the current study that there were no spill-over effects of knowledge, attitudes or behavioural intentions to non-targeted students following the six-session HFA anti-stigma program may be reflective of the insensitivity of the measures used to detect such changes. It is also possible that change in knowledge and attitudes is highly dependent on who transmits the information about HFA, with a student peer being viewed as a less credible source than either an adult presenter or a person with HFA themselves.

The finding that online activity usage affected participants’ knowledge over time is consistent with the results of studies which have found that internet-based programs can moderately improve outcomes in educational interventions (Nguyen et al., 2004). However, the finding that online activity usage did not affect participants’ attitudes or behavioural intentions over time is inconsistent with such research. A plausible explanation for why there was no effect of online activity usage on participants' attitudes or behavioural intentions towards their HFA peers may relate to the extent of engagement with the online activities, although there was no direct evaluation of this within the study. In contrast, it is unsurprising that there was a difference in knowledge between high and non-online activity users since the online reflection questions were knowledgebased. Given that the difference between user-types was evident only at follow-up, it is plausible to suggest that while the effects of the anti-stigma program decay over time for those who do not use the online activities, they remain stable for those who do.

With respect to the failure to observe predicted changes in behavioural intentions, there are a number of plausible explanations. First, given Ajzen’s Theory of Planned Behaviour (TpB; 1991) which posits that intention to engage in a given behaviour is causally linked to one’s attitude towards that behaviour, the observed change in attitudes should have contributed to a change in behavioural intentions. However, given that the attitudinal change found in this study was relatively small, it may be that it was not sufficiently powerful to generate discernible changes in behavioural intentions. Since research provides little support for a direct relation between knowledge and behavioural intention (Li, Scott and Li, 2008; Wakefield and Chaloupka, 2000), it is unsurprising that the large knowledge effect alone was insufficient to cause a change in participants’ behavioural intentions. Second, the gender of participants - namely, all males - may have been a factor countervailing the anticipated effect on behavioural intentions. For example, the fact that the program presenter and guest speakers 
were female may have impacted negatively upon their status as authority figures for an adolescent male audience (Carli, 1999). Further, research has indicated that males are less likely than females to respond positively to people with disabilities (Rosenbaum et al., 1988). Third, time may have played a role in detecting effects. It is possible that changes in behavioural intentions could have occurred immediately after certain sessions but then decayed rapidly. The post-test measure occurred one month after the guest-speaker session and thus, it is possible that any behavioural intentions that did occur due to this session had eroded. Fourth, the measurement tool utilised to detect behavioural intentions may have been inappropriate for the specific cohort to whom it was administered. Despite validation of the modified SAQ for use with adolescents, the questions asked may have been incongruent with the age-, gender-and culture-specific social norms of Australian males in seventh-, eighthand ninth-grade.

The findings of this study should be interpreted in light of a number of limitations. First, the generalizability of the results is restricted by the sample of participants, who were males aged between 13 and 16, from predominantly middle-class backgrounds. Future research should seek to determine whether the same or different effects can be found for adolescent girls and for students in senior high-school grades. Second, it is unknown whether the self-report responses of participants in the current study are reflective of actual attitudes or behavioural intentions, as the study did not seek to observe these variables in a naturalistic setting. Future studies should compare questionnaire responses with the actual behaviour of respondents in the school environment. With respect to behavioural intentions, the lack of significant results may also reflect the need for a greater period of time to develop friendships between individuals with HFA and their normally developing peers. Future studies would benefit from a more longitudinal framework for the observation of actual behavioural change. Third, participants in the study may have lacked incentive to complete the online component of the program diligently, and thus it is unknown whether this would have improved the effects of the intervention on all three dependent variables. Future research should seek to provide participants with sufficient motivation to complete the program's online activities in a timely manner. Fourth, the experimental design of the study did not allow for measurement of the effect of the program presenter’s and guest speaker's gender (both female) on the dependent variables. Thus, it is unknown whether this was an intervening variable in the study. Although the effect of information provided by male versus female parents on peers' cognitive and behavioural attitudes towards an autistic child has been examined (Morton and Campbell, 2008), no such comparison has been made for professionals or individuals with HFA. Future research should include conditions for both male and female presenters/guest speakers in order to determine whether the gender of the presenter/guest speaker has a 
discernible effect on participants. Fifth, the last program session and the post-test measures were administered following a school-holiday break. Given that there were no measures administered prior to the break, it is unknown whether there was a decay effect. Future studies should include regular measurement of the dependent variables throughout the program to determine whether there are any significant effects on the variables at particular intervals and whether they decay over time.

A final limitation related to the pragmatic difficulties of the randomisation process. The participating school allocates students to classes predominantly according to academic ability, referred to as 'streaming'. Students with HFA commonly have areas of academic difficulty, which results in their disproportionate allocation. The decision to exclude one of the classes from the randomisation process due to a higher proportion of HFA students (relative to the remaining classes) means that the randomisation may be better referred to as a 'pseudo-randomisation’ process. The implication is that the intervention groups and the peer control groups may have been less comparable, given that some of the participants (in the class with a higher proportion of HFA peers) may have developed attitudes, behaviours and knowledge with respect to HFA as a result of their exposure to such peers. This was an unavoidable limitation in an ecologically valid research study, however future research should seek to ensure that either true randomisation occurs, or otherwise that measures are taken to account for potential population differences.

Given that neither the present study nor previous studies have found a direct effect of HFA anti-stigma interventions on adolescent behavioural intentions, future research should seek to address this gap. Further, since this study is the first to empirically evaluate the efficacy of directive information as a means for augmenting knowledge, attitude and behavioural change, future research should also compare the combined effects of descriptive, explanatory and directive information with the combined effects of descriptive and explanatory information only. This would ascertain whether there is any significant benefit to including directive information in HFA anti-stigma interventions. While it has been argued that anti-stigma programs should commence at an earlier stage of mainstream education (Schacter et al., (2008), continued efforts to ameliorate the distress that many HFA students experience in high school is warranted, given that it is at this stage of their educational experience that they experience the greatest confluence of social demands and their social skills difficulties.

In conclusion, the results of the current study provide some preliminary evidence for the effectiveness of multi-component HFA anti-stigma programs for adolescent students in mainstream schools. In particular, the findings of this study indicate that multi-session programs which incorporate a combination of descriptive, 
explanatory and directive information can improve the knowledge and attitudes of adolescent boys towards their HFA peers. Furthermore, these changes can be sustained for at least one school term. These research findings represent a significant contribution to the literature on reducing the stigmatisation of HFA students in inclusive educational environments. That is, based upon the results of this study, it would seem reasonable to suggest that multi-session programs incorporating combined information (via face-to-face and online education; and both direct and video contact with individuals experiencing HFA) should be used with adolescent boys when attempting to facilitate their acceptance of their HFA peers in mainstream schools. Since it is likely that children with HFA will continue to be educated in mainstream educational settings, it is important that research continues in this area in order to establish the most effective means of reducing the stigmatisation of these students.

\section{Acknowledgements}

The authors extend appreciation to the parents, students and teachers of Edmund Rice College, Wollongong for their participation in this study. Special recognition must go to Dr Leonie Miller for her guidance regarding data analysis and interpretation and to Mr Greg Carey for his continued support and assistance during this project. 


\section{References}

Ajzen, I. (1991). The theory of planned behaviour. Organisational Behaviour and Human Decision Processes, $50,179-211$. http://www.cas.hse.ru/data/816/479/1225/Oct\%2019\%20Cited\%20\%231\%20Manage\%20THE\%20TH EORY\%20OF\%20PLANNED\%20BEHAVIOR.pdf. Accessed at 24 August 2012.

Attwood, T. (2006). Asperger’s syndrome. Tizard Learning Disability Review, 11, 3-11. doi: $10.1108 / 13595474200600032$

Autism Society of America (2004). Growing up together: Teens with autism [Fact Sheet]. http://www.autismsociety.org/site/DocServer/Growing_Up_Brochure_May_2004.pdf?docID=1561\&AddInterest=1041. Accessed 20 January 2012.

Baron-Cohen, S., Scott, F.J., Allison, C., Williams, J., Bolton, P., Matthews, F.E., \& Brayne, C. (2009). Prevalence of autism-spectrum conditions: UK school-based population study. British Journal of Psychiatry, 194, 500-509, doi: 10.1192/bjp.bp.108.059345

Campbell, J.M. (2005a). Introducing a student with autism to typical peers. Paper presented at the meeting of the Organisation for Autism Research, Applied Autism Research and Intervention Conference. Arlington, VA. http://www.researchautism.org/news/conference/speakers/index.asp. Accessed 25 July 2011.

Campbell, J.M. (2006). Changing children’s attitudes toward autism: A process of persuasive communication. Journal of Developmental and Physical Disabilities, 18, 251-272, doi: 10.1007/s10882-006-9015-7

Campbell, J. M. (2007). Middle school students' response to the self introduction of a student with autism: Effects of perceived similarity, prior awareness, and educational message. Remedial and Special Education, 28, 163-173, doi: 10.1177/07419325070280030501

Campbell, J.M. (2008). Reliability and validity of the Shared Activities Questionnaire as a measure of middle school students' attitudes toward autism. Journal of Autism and Developmental Disorders, 38, 15981604, doi: 10.1007/s10803-007-0534-6

Campbell, J. M., Morgan, S. B., \& Jackson, J. N. (2003). Autism spectrum disorders and mental retardation. In 
R. T. Brown (Ed.), Handbook of pediatric psychology in school settings (pp. 431-450). Mahwah, NJ: Lawrence Erlbaum.

Campbell, J. M., Ferguson, J. E., Herzinger, C. V., Jackson, J. N., \& Marino, C. A. (2004). Combined descriptive and explanatory information improves peers’ perceptions of autism. Research in Developmental Difficulties, 25, 321-339, doi:10.1016/j.ridd.2004.01.005

Carli, L. (1999). Gender, interpersonal power and social influence. Journal of Social Issues, 55, 81-99, doi: $10.1111 / 0022-4537.00106$

Baio, J. (2012). Prevalence of Autism Spectrum Disorders - Autiam and Developmental Disabilities Monitoring Network. Centers for Disease Control and Prevention: Morbidity and Mortality Weekly Report (2012). Surveillance Summaries, 61 (3) http://www.cdc.gov/mmwr/preview/mmwrhtml/ss6103a1.htm?s_cid=ss6103a1_w (accessed 28/02/13)

Chan, J. N., Mak, W. S., \& Law, L. C. (2009). Combining education and video-based contact to reduce stigma of mental illness: “The Same or Not the Same” anti-stigma program for secondary schools in Hong Kong. Social Science and Medicine, 68, 1521-1526, doi:10.1016/j.socscimed.2009.02.016

Corrigan, P. W., River, L., Lundin, R. K., Penn, D. L., Uphoff-Wasowski, K., Campion, J., et al. (2001). Three strategies for changing attributions about severe mental illness. Schizophrenia Bulletin, 27, 187-195. http://schizophreniabulletin.oxfordjournals.org/content/27/2/187.full.pdf. Accessed 12 June 2011.

Corrigan, P.W., Lurie, B.D., Goldman, H.H., Slopen, N., Medasani, K., \& Phelan, S. (2005). How adolescents perceive the stigma of mental illness and alcohol abuse. Psychiatric Services, 56, 544-550. http://www.ps.psychiatryonline.org/cgi/reprint/56/5/544. Accessed 12 June 2011.

Coulter, D. (2006). Intricate minds: Understanding classmates with Asperger Syndrome [DVD]. London, UK: Coultervideo.

Crisp, A., Gedler, M., Rix, S., Meltzer, H., \& Rowlands, O. (2000). Stigmatisation of people with mental illnesses. British Journal of Psychiatry, 177, 4-7, doi: 10.1192/bjp.177.1.4

Essler, V., Arthur, A., \& Stickley, T. (2006). Using a school-based intervention to challenge stigmatizing attitudes and promote mental health in teenagers. Journal of Mental Health, 15, 243-25, doi: $10.1080 / 09638230600608669$

Faherty, C. (2005). Understanding friends. TEACCH: The University of North Carolina. http://teacch.com/educational-approaches/understanding-friends. Accessed 16 May 2011.

Ferraioli, S.J., \& Harris, S.L. (2011). Effective educational inclusion of students on the autism spectrum. Journal 
of Contemporary Psychotherapy, 41, 19-28, doi: 10.1007/s10879-010-9156-y

Gray, D. E. (1993). Perceptions of stigma: The parents of autistic children. Sociology of Health and Illness, 15, 102-120, doi: 10.1111/1467-9566.ep11343802

Gray, D.E. (2002). 'Everybody just freezes. Everybody is just embarrassed’: Felt and enacted stigma among parents of children with high functioning autism. Sociology of Health and Illness, 24, 734-749, doi: $10.1111 / 1467-9566.00316$

Gray, C. (2002). The sixth sense II. Arlington, TX: Future Horizons.

Harrower, J.K., \& Dunlap, G. (2001). Including children with autism in general education classrooms: A review of effective strategies. Behaviour Modification, 25, 762-784, doi: 10.1177/0145445501255006

Kasari, C., Freeman, S.F.N., Bauminger, N., \& Alkin, M.C. (1999). Parental perspectives on inclusion: effects of autism and down-syndrome. Journal of Autism and Developmental Disorders, 29, 297-305, doi: 10.1023/A:1022159302571

Leach, D.J., \& Byrne, M.K. (1986). Some spill-over effects of a home based reinforcement. Educational Psychology, 6, 265-276, doi: 10.1080/0144341860060304

Li, Y., Scott, C.S., \& Li, L. (2008). Chines nursing students’ HIV/AIDS knowledge, attitudes and practice intentions. Applied Nursing Research, 21, 147-152, doi: 10.1016/j.apnr.2006.10.004

Ling, C., Mak, W., \& Cheng, J. (2010). Attribution model of stigma towards children with autism in Hong Kong. Journal of Applied Research in Intellectual Disabilities, 23, 237-249, doi: 10.1111/j.14683148.2008.00456.x

Lisser, M., \& Westbay, J. (2001). Making friends with aliens: Inclusion and collaborative autobiography. In L. Andron, (Ed.), Our Journey through High Functioning Autism and Asperger Syndrome: A Roadmap, (pp 133-175). Philadelphia, PA: Jessica Kingsley Publishers.

McDonald, S., Birnbrauer, J. S., \& Swerissen, H. (1987). The effect of an integration program on teacher and student attitudes to mentally-handicapped children. Australian Psychologist, 22, 313- 322, doi: $10.1080 / 00050068708259532$

Morgan, S.B., Walker, M., Bieberich, A., \& Bell, S. (1996). The shared activities questionnaire. Unpublished manuscript. University of Memphis, Memphis, TN.

National Autistic Society (2008, January 18). Autism: National Autistic Society - Part 2 (socially awkward) [Video File]. http://www.youtube.com/watch?v=_WSQLXVtTQg\&feature=related. Accessed 15 January 2012. 
National Autistic Society (2008, October2). Autism: National Autistic Society anti-bullying campaign [Video File]. http://www.youtube.com/watch?v=1WLQjGpGUvc. Accessed 15 January 2012.

Nguyen, H.Q., Carrieri-Kohlman, V., Rankin, S.H., Slaughter, R., \& Stulbarg, M.S. (2004). Internet-based patient education and support interventions: A review of evaluation studies and directions for future research. Computers in Biology and Medicine, 31, 95-112, doi: 10.1016/S0010-4825(03)00046-5

Pinfold, V., Toulmin, H., Thornicroft, G., Huxley, P., Farmer, P., \& Graham, T. (2003). Reducing psychiatric stigma and discrimination: Evaluation of educational interventions in UK secondary schools. British Journal of Psychiatry, 182, 342-346, doi: 10.1192/bjp.02.375

Pinfold, V., Thornicroft, G., Huxley, P., \& Farmer, P. (2005). Active ingredients in anti-stigma programmes in mental health. International Review of Psychiatry, 17, 123-131, doi: 10.1080/09540260500073638

Rosenbaum, P. L., Armstrong, R. W., \& King, S. M. (1988). Determinants of children's attitudes toward disability: A review of the evidence. Children's Health Care, 17, 1-8, doi 10.1207/s15326888chc1701_5

Rydell, S.A., French, S.A., Fulkerson, J.A., Neumark-Sztainer, D., Gerlach, A.F., Story, M., et al. (2005). Use of a web-based component of a nutrition and physical activity behavioural intervention with girl scouts. Journal of the American Dietetic Association, 105, 1447-1450, doi: 10.1016/j.jada.2005.06.027

Schachter, H.M., Girardi, A., Ly, M., Lacriox, D., Lumb, A.B., van Berkom, J., et al. (2008). Effects of schoolbased interventions on mental health stigmatization: A systematic review. Child and Adolescent Psychiatry and Mental Health, 2, 2-18. doi: 10.1186/1753-2000-2-18

Schulze, B., Richter-Werling, M., Matschinger, H., \& Angermeyer, M. C. (2003). "Crazy? So what!" Effects of a school project on students' attitudes towards people with schizophrenia. Acta Psychiatrica Scandinavica, 107, 142-150, doi: 10.1034/j.1600-0447.2003.02444

Siperstein, G. N. (1980). Development of the Adjective Checklist: An instrument for measuring children's attitudes toward the handicapped. Unpublished manuscript, University of Massachusetts, Boston, MA.

Siperstein, G. N., \& Bak, J. (1977). Instruments to measure children's attitudes toward the handicapped: Adjective Checklist and Activity Preference List. Unpublished manuscript, University of Massachusetts, Boston, MA.

Stefanski, D. (2011). How to talk to an autistic kid. Mineapolis, MN: Free Spirit Publishing Inc. Swaim, K.F., \& Morgan, S.B. (2001). Children’s attitudes and behavioural intentions toward a peer with autistic 
behaviours: Does a brief educational intervention have an effect? Journal of Autism and Developmental Disorders, 31, 195-205, doi: 10.1023/A:1010703316365

Townley, M. (2002). Mental health needs of children and young people. Nursing Standard, $16,38-47$. http://search.proquest.com.ezproxy.uow.edu.au/docview/219824929/fulltextPDF?accountid=15112. Accessed 10 June 2011.

Wakefield, M., \& Chaloupka, F. (2000). Effectiveness of comprehensive tobacco control programmes in reducing teenage smoking in the USA. Tobacco Control, 9, 177-1 86, doi: 10.1136/tc.9.2.177

Wallach, H. S. (2004). Changes in attitudes towards mental illness following exposure. Community Mental Health Journal, 40, 235-248, doi: 1023/B:COMH.0000026997.92083.4d

Watson, A.C., Otey, E., Westbrook, A.L., Garder, A.L., Lamb, T.A., Corrigan, P.W., et al. (2004). Changing middle schoolers' attitudes about mental illness through education. Schizophrenia Bulletin, 30, 563-572. http://schizophreniabulletin.oxfordjournals.org/content/30/3/563.full.pdf+html. Accessed 10 June 2011.

Weiner, B., \& Graham, S. (1984). An attributional approach to emotional development. In C. E. Izard, J. Kagan, \& R. B. Zajonc (Ed.), Emotions, cognition, and behaviour (pp. 167-191). New York: Cambridge University Press.

Welton, J. (2004). Can I tell you about Asperger Syndrome? A guide for friends and family. London, UK: Jessica Kingsley Publishers. 
Appendix

Session-by-Session Outline of the 'Understanding Our Peers' Program

\begin{tabular}{|c|c|c|c|c|c|c|}
\hline & One & Two & Three & Sion & Five & Six \\
\hline Goal & $\begin{array}{l}\text { To introduce students to the impairments in } \\
\text { higher-functioning autism. }\end{array}$ & $\begin{array}{l}\text { To improve student knowledge of higher- } \\
\text { functioning autism. }\end{array}$ & 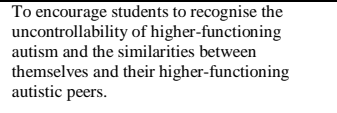 & $\begin{array}{l}\text { To improve students' ability to interact with } \\
\text { individuals with higher-functioning autism. }\end{array}$ & $\begin{array}{l}\text { To oimprove studdent knowledge end } \\
\text { understanding of hihher-functioning autism } \\
\text { through presentations from guest speakers. }\end{array}$ & To review key learning outcomes. \\
\hline Learning outcome/s & $\begin{array}{l}\text { Students learn about the perceptual } \\
\text { perspective-taking, cognitive perspective- } \\
\text { taking and affective perspective taking } \\
\text { impairments in higher-functioning autism. }\end{array}$ & $\begin{array}{l}\text { Students learn about the core symptoms of } \\
\text { higher-functioning autism as related to the } \\
\text { domains of socialisation, communication } \\
\text { and behaviour. } \\
\text { Students learn about the challenges faced by } \\
\text { those with higher-functioning autism from } \\
\text { the perspective of those with the disorder. }\end{array}$ & 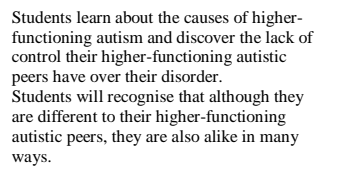 & $\begin{array}{l}\text { Students learn effective strategeies for } \\
\text { interacting with their pers with higher- } \\
\text { functioning autism. }\end{array}$ & $\begin{array}{l}\text { Students learn about how higher functioning } \\
\text { autism affects the lives of those diagnosesed } \\
\text { from the perspective of an individual with } \\
\text { the condition and a professional in the field. }\end{array}$ & $\begin{array}{l}\text { Students review what they have learnt } \\
\text { throughout the program. } \\
\text { Sttudents reflect on their own personal } \\
\text { experience of the program. }\end{array}$ \\
\hline In-session description & 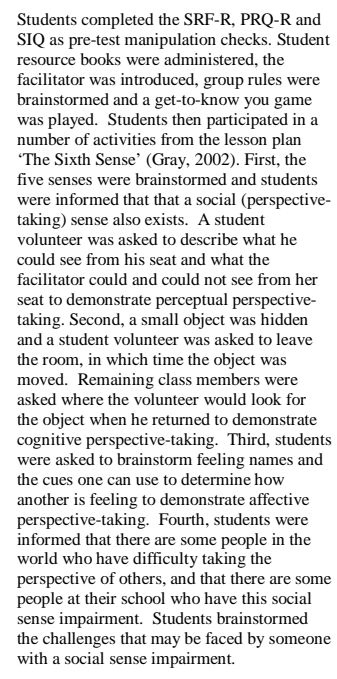 & 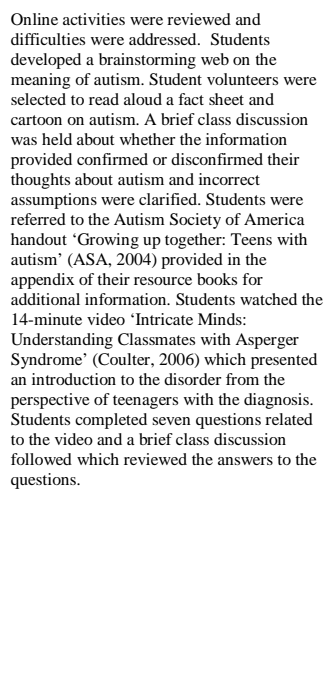 & 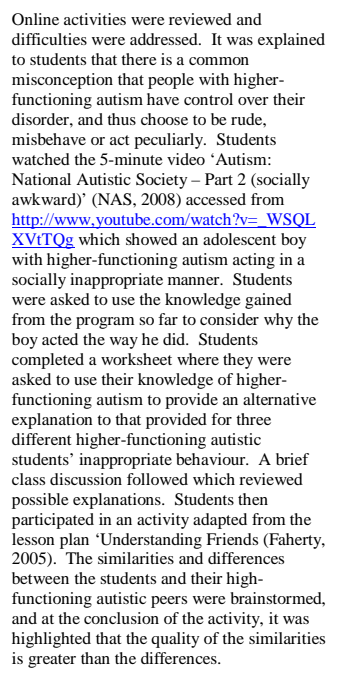 & 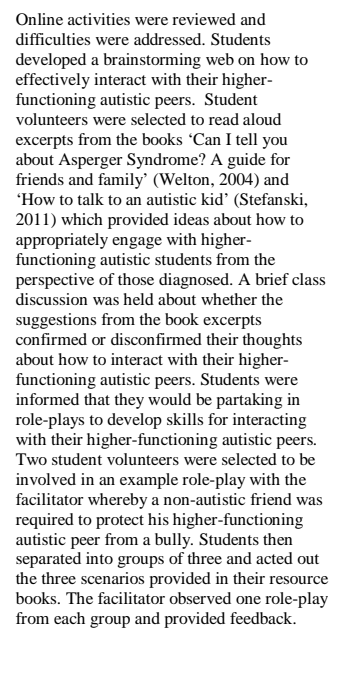 & 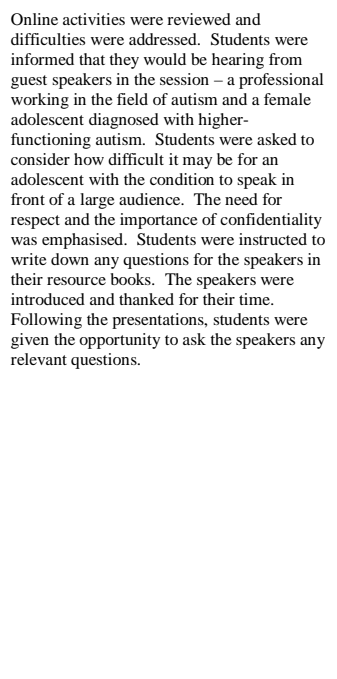 & 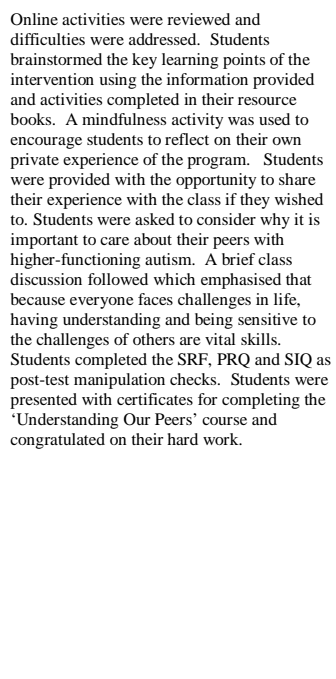 \\
\hline $\begin{array}{l}\text { At-home online activity description } \\
\text { Online reflection }\end{array}$ & $\begin{array}{l}\text { Students were instructed to “reflect back to } \\
\text { week one of the 'Understanding our Peers' } \\
\text { program and wwite down thee things you } \\
\text { learnt from the session". }\end{array}$ & $\begin{array}{l}\text { Students were instructed to "reflect back to } \\
\text { ween two of the "Understanding our Peers' } \\
\text { program and write down three things you } \\
\text { learnt from the session". }\end{array}$ & $\begin{array}{l}\text { Students were instructed to "reflect back to } \\
\text { week three of the "Understanding our Peers' } \\
\text { program and write down three things you } \\
\text { learnt from the session". }\end{array}$ & $\begin{array}{l}\text { Students were instructed to "reflect back to } \\
\text { week four of the 'Understanding our Peers' } \\
\text { program and writid down three things you } \\
\text { learnt from the session". }\end{array}$ & $\begin{array}{l}\text { Students were instructed to "reflect back to to } \\
\text { week five of the 'Understanding our Peers' } \\
\text { program and write down three things you } \\
\text { learnt from the session". }\end{array}$ & No online reflection. \\
\hline Online discussion & $\begin{array}{l}\text { Students were instructed to imagine having a } \\
\text { child that fails so develop normanlly and } \\
\text { asked to reflect on how this would feel. }\end{array}$ & $\begin{array}{l}\text { Students were asked to reflect on whether } \\
\text { the perents of children with higher- } \\
\text { functioning autiss should inform the school } \\
\text { of their child's disorder, and to provide } \\
\text { reasons for why or why not. }\end{array}$ & 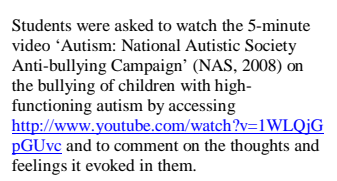 & $\begin{array}{l}\text { Students were asked to reflect on whether } \\
\text { children with higher -functioning autusism } \\
\text { should receive the same discinine at schol } \\
\text { as their peers, and to provide reasons for } \\
\text { why or why not. }\end{array}$ & 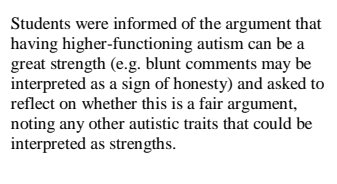 & No online discussion. \\
\hline
\end{tabular}


Table 1.

Means and Standard Deviations of AKQ, ACL and SAQ for all Conditions at Pre-test, Post-test and Follow-up

\begin{tabular}{|c|c|c|c|c|c|c|}
\hline & \multicolumn{2}{|c|}{$\begin{array}{l}\text { Intervention } \\
\quad(\mathrm{N}=46)\end{array}$} & \multicolumn{2}{|c|}{$\begin{array}{c}\text { No-intervention peer } \\
(\mathrm{N}=66)\end{array}$} & \multicolumn{2}{|c|}{$\begin{array}{l}\text { No-intervention non-peer } \\
(\mathrm{N}=283)\end{array}$} \\
\hline & $\mathrm{M}$ & SD & $\mathrm{M}$ & SD & $\mathrm{M}$ & SD \\
\hline & \multicolumn{6}{|c|}{ Autism Knowledge Questionnaire } \\
\hline Pre-test & 4.32 & 1.33 & 4.17 & 1.90 & 3.97 & 1.57 \\
\hline Post-test & 7.93 & 2.02 & 4.71 & 2.18 & 4.06 & 1.66 \\
\hline \multirow[t]{2}{*}{ Follow-up } & 7.43 & 2.04 & 4.77 & 1.88 & 4.31 & 1.85 \\
\hline & \multicolumn{6}{|c|}{ Adjective Checklist } \\
\hline Pre-test & 18.89 & 4.27 & 21.77 & 5.99 & 20.99 & 4.64 \\
\hline Post-test & 22.41 & 4.29 & 21.71 & 5.29 & 21.72 & 5.06 \\
\hline \multirow[t]{2}{*}{ Follow-up } & 21.41 & 5.98 & 20.39 & 4.15 & 21.74 & 5.50 \\
\hline & \multicolumn{6}{|c|}{ Shared Activities Questionnaire } \\
\hline Pre-test & 70.43 & 20.64 & 72.81 & 20.93 & 77.24 & 19.68 \\
\hline Post-test & 72.25 & 21.77 & 70.55 & 21.31 & 73.50 & 21.51 \\
\hline Follow-up & 69.64 & 20.41 & 69.09 & 22.79 & 73.54 & 21.25 \\
\hline
\end{tabular}


HIGHER-FUNCTIONING AUTISM ANTI-STIGMA PROGRAM 28

\section{Footnotes}

1. There remains considerable debate over the differentiation of Asperger's Disorder and autism in higher functioning individuals and whether they are the same or two separate and distinct disorders (Attwood, 2006). Given the ongoing nature of this debate, the present study will defer to the ubiquitous term HFA in reference to those at the higher functioning end of the autism spectrum. 